\title{
Metodologias ativas na educação profissional e tecnológica: breve teorização
}

\author{
Active methodologies in professional and technological education: brief theorization \\ Metodologías activas en la formación profesional y tecnológica: breve teorización
}

\section{Resumo}

Este artigo propõe uma breve revisão teórica sobre o uso das metodologias ativas na educação profissional e tecnológica. Para tal, fez-se necessário refletir sobre a educação profissional no ensino médio integrado e como a Base Nacional Comum Curricular influencia este contexto. A partir dessa reflexão, o trabalho também analisa o uso das metodologias ativas e tecnologias de informação e comunicação aplicadas na área, bem como a formação dos professores no uso destes recursos. Assim, as discussões levantadas durante a teorização possibilitaram o entendimento de que é necessário romper com a dualidade aluno (nativo digital) e professor (estrangeiro digital) se o que se objetiva é uma proposta pedagógica que aproxime minimamente as diferenças geracionais entre ambos. Destarte, é necessário despertar para multiplicidade de questões que envolvem o uso dessas novas metodologias e tecnologias, pois ainda são incipientes as discussões aprofundadas sobre a sua inclusão nos projetos pedagógicos, percursos formativos e capacitações para professores. Espera-se que esse levantamento bibliográfico possa conduzir a uma discussão qualificada ou infusão de uma educação protagonista, ativa e reflexiva no âmbito da educação profissional.

Palavras-chave: Tecnologias de informação e comunicação; Metodologias ativas; Educação profissional e tecnológica.

\begin{abstract}
This article proposes a brief theoretical review on the use of active methodologies in professional and technological education. To do so, it was necessary to reflect on professional education in integrated high school education and how the Common National Curriculum Base influences this context. Based on this reflection, the work also analyzes the use of active methodologies and information and communication technologies applied in the area, as well as the training of teachers in the use of these resources. Thus, the discussions raised during theorization made it possible to understand that it is necessary to break with the duality of student (digital native) and teacher (digital foreigner) if what is aimed at is a pedagogical proposal that minimally approximates the generational differences between both. Thus, it is necessary to wake up to the multiplicity of issues involving the use of these new methodologies and technologies, as in-depth discussions on their inclusion in pedagogical projects, training paths and teacher training are still incipient. It is hoped that this bibliographic survey can conduct to a qualified discussion or infusion of a protagonist, active and reflective education within the scope of professional education.
\end{abstract}

Keywords: Information and communication technologies; Active methodologies; Professional and technological education.

\section{Resumen}

Este artículo propone una breve revisión teórica sobre el uso de metodologías activas en la educación profesional y tecnológica. Para ello, fue necesario reflexionar sobre la formación profesional en la escuela secundaria integrada y cómo la Base Curricular Común Nacional influye en este contexto. A partir de esta reflexión, el trabajo también analiza el uso de metodologías activas y tecnologías de la información y la comunicación aplicadas en el área, así como la formación del profesorado en el uso de estos recursos. Así, las discusiones planteadas durante la teorización permitieron entender que es necesario romper con la dualidad del alumno (nativo digital) y profesor (entrangero digital) si lo objetivo es una propuesta pedagógica que se aproxime mínimamente a las diferencias generacionales entre ambos. Por lo tanto, es necesario despertar a la multiplicidad de cuestiones que involucran el uso de estas nuevas metodologías y tecnologías, porque las discusiones en profundidad sobre su inclusión en proyectos pedagógicos, itinerarios de capacitación y capacitación para los profesores son aún incipientes. Se espera que este estudio bibliográfico pueda conducir a una 
discusión cualificada o a la infusión de una educación protagonista, activa y reflexiva en el campo de la educación profesional.

Palabras clave: Tecnologías de la información y las comunicaciones; Metodologías activas; Educación profesional y tecnológica.

\section{Introdução}

Para Libâneo (2013), a prática educacional é um fenômeno universal e social, inerente à natureza humana, no qual é imprescindível à essência e ao funcionamento da sociedade. Desse modo, a Educação Profissional e Tecnológica (EPT), em especial, tem sido apreciada prioritariamente sob o prisma do percurso formativo e organização curricular, com menor amplitude de discussão em metodologias de aprendizagem voltadas para a construção e desenvolvimento de competências profissionais (Barbosa \& Moura, 2013). Ainda segundo os autores, o modelo atual educacional possui poucas chances de sobrevivência nas próximas décadas, pois no Brasil ainda não temos uma avaliação sistêmica.

De acordo com Macedo et al. (2019), o sistema educacional mantém-se firmado na fragmentação do saber em forma de currículos. Severo (2018) complementa ainda que as unidades de ensino continuam sendo delimitadas de forma superficial por conteúdos estanques (fechados e isolados), conduzindo o docente ao cumprimento de planos de ensino. Araújo e Frigotto (2015), apresentam os princípios orientadores de um currículo integrado baseado na contextualização, interdisciplinaridade e o compromisso com a transformação social. Para Andrade e Ferrete (2019), o currículo deve ser construído levando em consideração a vida, experiências e cultura de cada pessoa.

Barbosa e Moura (2013) alertam para o cenário atual: escolas alicerçadas no século XIX, com professores formados no século XX e alunos do século XXI. Dessa constatação surge a problemática levantada pelos autores: Para que a EPT atenda às necessidades atuais do mundo do trabalho, quais mudanças deverão ocorrer no âmbito do contexto escolar, prática docente e perfil do aluno?

Torna-se necessário que os egressos da EPT consigam desenvolver-se em um mundo cada vez mais complexo e repleto de tecnologias inovadoras (Barbosa \& Moura, 2013). Os alunos, em especial aqueles do Ensino Médio Integrado (EMI), modalidade de ensino de formação básica e técnica, cujo objetivo é o desenvolvimento omnilateral (Frigotto, Ciavatta \& Ramos, 2005), autônomo, crítico, ativo e transformador (Santos et al., 2018), advindos da geração Z, não aprendem da mesma forma que seus professores (geração X e Y) aprenderam (Andrade et al., 2020).

O aluno que nasceu e cresceu cercado pelas novas tecnologias como celulares, videogames, internet, dentre outros, é caracterizado como um "nativo digital” (Palfrey \& Gasser, 2011). Desse modo, torna-se necessário romper com o modelo tradicional de educação centrado na abstração, no poder do verbo para a habilidade que o mundo do trabalho requer do futuro profissional no uso das tecnologias (Barbosa \& Moura, 2013).

Em contraponto, Andrade e Ferrete (2019) salientam que somente a tecnologia e o aluno moderno não se bastam. É necessário também experimentar uma Metodologia Ativa (MA) e consequentemente construir um novo conceito de aluno reflexivo, autônomo e protagonista. Salienta-se, entretanto, que os esforços em busca de metodologias que favoreçam o desenvolvimento desse perfil de aluno não são recentes.

Dessa maneira, surge durante o movimento denominado de Nova Escola entre o final do século XIX e o início do século XX na Inglaterra, dos pensadores Édouard Claparéde, William James e John Dewey, a Metodologia Ativa (MA) baseada nas experiências e na autonomia do aluno, com o objetivo principal de superar o tradicionalismo nas escolas (Andrade et al., 2020).

A MA é fundamentada em ações como ler, escrever, perguntar, discutir ou estar envolvido na resolução de problemas e/ou desenvolvimento de projetos. São realizadas também atividades mentais de alto nível como análise, síntese e avaliação. O professor é somente um facilitador, orientador ou supervisor das atividades. Um ambiente de aprendizagem ativa é caracterizado pela atitude ativa da inteligência contrapondo à atitude passiva dos métodos tradicionais de ensino (Barbosa \& Moura, 2013). 
Diesel, Baldez e Martins (2017) descreveram sete princípios que constituem as metodologias ativas de ensino, sendo: autonomia, reflexão, problematização da realidade, trabalho em equipe, inovação, professor: mediador, facilitador e ativador, aluno: centro do ensino e de aprendizagem.

Posto isto, o presente artigo tem como objetivo proceder uma breve discussão teórica, a partir de um levantamento bibliográfico, sobre a utilização da Metodologia Ativa na Educação Profissional e Tecnológica sob o ponto de vista do arcabouço teórico existente, no intuito de levantar algumas questões a respeito da temática e suscitar novos debates. Para tal, o artigo em tela está organizado da seguinte forma: discussão inicial sobre a Educação Profissional e Tecnológica no ensino médio integrado, as principais metodologias ativas e as Tecnologias da Informação e Comunicação (TIC's) aplicadas à Educação Profissional e Tecnológica e, por fim, a formação dos professores no uso da MA e TIC's.

\section{Metodologia}

Para a realização deste trabalho fez-se a opção por uma pesquisa de levantamento bibliográfico baseada nas ideias de Severino (2007) quando o mesmo diz que esse tipo de pesquisa se respalda em fontes impressas ou eletrônicas que contenham dados oriundos de investigação científica com cunho metodológico.

Gil (2002, p. 44-45) ainda acrescenta que esse tipo de pesquisa é “[...] desenvolvida com base em material já elaborado, constituído principalmente de livros e artigos científicos”.

A abordagem escolhida foi a qualitativa que permite que a imaginação e criatividade do pesquisador sejam afloradas, no intuito de expandir para novos olhares a respeito de determinada temática (Godoy, 1995), buscando assim novas reflexões e roupagens acerca do recorte teórico escolhido.

\section{Resultados e Discussão}

\subsection{A Educação Profissional e Tecnológica no Ensino Médio Integrado}

O ensino brasileiro nasceu da dualidade dos sistemas de ensino público e privado e da dualidade das propostas educacionais (formação científica e formação técnica). A junção público/privado teve como finalidade específica de ensinar os filhos das elites em detrimento da população mais pobre. Sua marca fundamental do descobrimento até o século XX foi de selecionar e não de incluir. Após a década de 1930, esta lógica permaneceu disfarçada em um outro molde: a educação profissional consolidada no Brasil pós década de 1940 teria uma característica mais seletiva ao indicar aqueles que seriam as classes dirigentes e aqueles que seriam destinados à classe trabalhadora (Barcellos et al., 2017).

Ainda segundo os autores, “a ideia de uma educação profissional para os menos favorecidos e de uma educação científica para os mais favorecidos vai orientar a construção de leis que regulam esta modalidade de ensino nos anos 1940" (Barcellos et al., 2017, p.121). A partir disso, a Educação no Brasil passou por quatro fases, de acordo com Saviani (2011): 15491759: predomínio da pedagogia tradicional religiosa; 1759-1932: pedagogia tradicional laica; 1932-1969: pedagogia nova; 19612001: pedagogia produtivista.

O Ensino Médio (EM) caracterizado pela Lei de Diretrizes e Bases da Educação (LDB) 9394/96 não é eminentemente propedêutico, ou seja, uma preparação para o Ensino Superior somente (Barcellos et al., 2017). A demanda atendida pela EPT é oriunda de diferentes contextos sociais, econômicos e culturais (Machado, 2008). Moura (2008) complementa ainda que existe divergência entre as práticas pedagógicas e os modelos culturais dos estudantes.

A EPT, por sua vez, aparece na LDB (1996) com um capítulo específico dedicado à mesma, cujo objetivo é ofertar formação técnica de nível médio em formato integrado, com articulação da formação geral e formação profissional (Kleiman \& Marques, 2018). A recomendação da Base Nacional Comum Curricular (BNCC) destaca que os jovens precisam desenvolver 
competências nas práticas digitais, tendo uma visão crítica, ética e estética e não somente técnica das TIC's e seus usos (Brasil, 2018, p.489).

No entanto, de acordo com Kleiman e Marques (2018), o discurso teórico se contrapõe às competências e habilidades sugeridas, devido especialmente à democratização dos recursos tecnológicos na sociedade. Cabe também à escola o letramento digital. Silveira, Gonçalves e Maraschin (2017) elucidam que a realidade das instituições muitas vezes é cercada por desafios e dificuldades, principalmente em relação ao público do qual essa política educacional se propõe a atender.

Em relação às habilidades básicas que faltam na formação dos jovens, Goldberg (2010) elenca sete, sendo: (1) fazer boas perguntas; (2) nomear objetos; (3) modelar processos e sistemas qualitativamente; (4) decompor problemas complexos em problemas menores; (5) coletar dados para análise; (6) visualizar soluções e gerar novas ideias; e (7) comunicar soluções de forma oral e por escrito. Em contraponto, Barbosa e Moura (2013), apontam o excesso de conteúdo na EPT e a dificuldade dos alunos em administrar este excesso conteudista. Andrade et al. (2020) complementam a constatação de que as salas de aulas brasileiras priorizam o conteúdo e de forma verticalizada.

\subsection{Metodologias ativas e TIC's aplicadas à educação profissional e tecnológica}

Como citado anteriormente, a MA teve sua insurgência na pedagogia nova e sua implantação na década de 1990 (Trevelin et al. 2013 \& Valente, 2014). É um anteposto à educação bancária tão discutida por Paulo Freire (2013) ou pela memorização mecânica citada por Carneiro (2012). Mattar (2017) apresenta várias formas de aplicar as MA's, conforme quadro 1 abaixo:

Quadro 1 - Possibilidades de Metodologias Ativas.

\begin{tabular}{|c|c|}
\hline Metodologia & Descrição \\
\hline $\begin{array}{l}\text { Blended Learning } \quad \text { (aprendizagem } \\
\text { híbrida) }\end{array}$ & Mistura de educação presencial e a distância (online). \\
\hline Sala de aula invertida & $\begin{array}{l}\text { - Apoiadas pelas Tecnologias Digitais de Informação e Comunicação (TDIC), atividades que } \\
\text { antes eram realizadas na sala de aula, ocorrem fora dela e vice-versa; } \\
\text { - Promove uma maior interação entre professor e aluno. }\end{array}$ \\
\hline Peer Instructions (Instrução entre pares) & $\begin{array}{l}\text { - Alunos ensinam e aprendem com seus colegas; } \\
\text { - É uma metodologia específica e sistemática que mede constantemente os resultados. }\end{array}$ \\
\hline Método de caso (Case method) & $\begin{array}{l}\text { - Alunos discutem e apresentam soluções para os casos propostos pelos professores; } \\
\text { - Alunos atuam na função de gestores e decisores, se posicionando em situações próximas ao } \\
\text { real. }\end{array}$ \\
\hline $\begin{array}{l}\text { Aprendizagem baseada em problemas e } \\
\text { problematização }\end{array}$ & $\begin{array}{l}\text { - Desenvolvida pela Faculdade de Medicina da Universidade MCMaster (Canadá); } \\
\text {-Alunos aprendem em pequenos grupos e com professores tutores, a partir de problemas. }\end{array}$ \\
\hline Aprendizagem baseada em projetos & $\begin{array}{l}\text {-Alunos aprendem trabalhando um longo período de tempo para investigar e responder a uma } \\
\text { questão, problema ou desafio, envolvente e complexo. }\end{array}$ \\
\hline Pesquisa & $\begin{array}{l}\text { - Produção de trabalhos para disciplinas, iniciação científica ou Trabalho de Conclusão de Curso } \\
\text { (TCC), onde o professor atua como orientador. }\end{array}$ \\
\hline $\begin{array}{l}\text { Aprendizagem baseada em games ou } \\
\text { gamificação }\end{array}$ & $\begin{array}{l}\text { - Utilizando games jogadores podem escolher como aprender, traçando seus objetivos de } \\
\text { aprendizagem ou com objetivos previamente definidos. }\end{array}$ \\
\hline Design Thinking & $\begin{array}{l}\text { - Propõe soluções criativas e inovadoras para problemas que utiliza a forma de pensar dos } \\
\text { designers. }\end{array}$ \\
\hline Avaliação por pares e auto avaliação & $\begin{array}{l}\text { - Alunos se deslocam da posição de recipientes e se tornam professores e observadores de si } \\
\text { mesmos. }\end{array}$ \\
\hline
\end{tabular}

Fonte: Mattar (2017). 
Baseado nas informações supracitadas, é possível observar pelo quadro 1, que as metodologias existem, mas a sua utilização não pode se dar de forma vaga e imprecisa, acreditando que toda aprendizagem é inerentemente ativa. Em oposição a esta constatação, pesquisas da ciência cognitiva sugerem que os alunos devem fazer algo mais do que apenas ouvir, para ter uma aprendizagem efetiva (Meyers \& Jones, 1993). Em consonância com as habilidades requeridas elencadas por Goldberg (2010) acima, Bonwell e Eison (1991) e Silberman (1996) citam que os alunos precisam realizar tarefas mentais de alto nível como análise, síntese e avaliação em uma aprendizagem que perpasse pela execução de algo e ao mesmo tempo a reflexão daquilo que se está fazendo.

Em uma pesquisa sobre o uso da MA em formato de estudo de caso em um curso de ensino médio integrado no Instituto Federal do Mato Grosso do Sul (IFMS) - Campus Nova Andradina, Lima et al. (2019) chegaram aos seguintes resultados: melhoria do relacionamento em sala de aula e na aplicação do conteúdo com resultados finais superiores nas avaliações via utilização de MA. Para tal, foi necessário adaptar o material para os discentes acessarem de qualquer local pelo telefone celular e foi utilizado também o programa de apresentação de slides PREZI - software online para criação de apresentações não lineares - formando um imenso mapa mental.

Por outro lado, a introdução da MA gerou adversidades, como: problemas curriculares de ensino/aprendizagem como empecilhos para a aplicação de MA; resistência dos discentes na implementação e dificuldade de preparação e organização, pois a metodologia exige maior trabalho do docente.

O uso da MA consiste também em aproveitar as TIC's para aguçar o cognitivo dos discentes e não somente ser uma ferramenta de consumo e sim uma nova dimensão educacional (Andrade \& Ferrete, 2019). Moran (2015) complementa que a tecnologia integra todos os espaços do mundo físico e digital.

Shah e Nihalani (2012) complementam ao mencionar elementos como bom humor, disposição e alegria como lubrificantes das engrenagens do entendimento e da aprendizagem. Andrade et al. (2020) sugerem uma pedagogia problematizadora com junção das TIC's, na qual o aluno é motivado a ter uma postura ativa na busca pela autonomia e protagonismo (Andrade \& Ferrete, 2019).

Para Moran (2015), as TIC's ampliam e facilitam a atualização de materiais, pesquisa online, comunicação entre alunos e professores e estes e seus pares, a propagação de projetos, suplantando os muros das escolas. Andrade e Ferrete (2019) salientam, contudo, que o conhecimento não pode ser pautado na unilateridade e sim na bilateridade (professor/aluno), em que o aluno não pode ser um mero executor e sim fundamentar e sustentar aquilo que se faz. É preciso criar um diálogo e não um monólogo.

Araújo (2011, p.39) destaca que é preciso reinventar a educação, uma vez que o modelo tradicional de escola consolidado no século XIX tem sido suplantado pelas novas demandas. Dessa forma, Barbosa e Moura (2013) indagam sobre o tipo de aprendizagem que precisamos na EPT. Para os autores esta resposta perpassa pelo aspecto de visão que olhamos para a diversidade educacional brasileira e da intensidade que percebemos os impactos das Tecnologias da Informação e Comunicação (TIC) não somente pelo âmbito da aprendizagem, mas também pelas exigências do mercado de trabalho.

A Educação Profissional Tecnológica requer aprendizagem significativa, contextualizada, orientada para o uso das TIC, que favoreça o uso intensivo dos recursos da inteligência, e que gere habilidades em resolver problemas e conduzir projetos nos diversos segmentos do setor produtivo. Em contraponto, a aprendizagem EPT deve estar cada vez mais distante da aprendizagem tradicional fundamentada no poder do verbo, teórica e dependente do uso intensivo da memória (Barbosa \& Moura, 2013, p.52).

O mundo empresarial incorporou de forma rápida as vantagens das TIC para ampliar suas fronteiras, aumentando a oferta de produtos e serviços baseados na economia do conhecimento (Valente, 2014). A Lei de Diretrizes e Bases da Educação LDB (1996) em seu Artigo 36 orienta para que o currículo do Ensino Médio adote metodologias de ensino e de avaliação que estimulem a iniciativa dos estudantes (Andrade et al., 2020). 


\subsection{Formação dos professores no uso de MA e TIC's}

Para Moura (2008, p. 27), existe uma "fragmentação das discussões dos grandes temas das agendas nacionais", sendo uma desta o âmbito educacional que inclui a Educação Profissional Tecnológica (EPT) e, consequentemente, os educadores que nela atuam.

A formação de um professor é um processo contínuo que envolve dois aspectos: a aprendizagem sobre o ensinar e a aprendizagem sobre como ser um professor.

O ensinar implica o desenvolvimento de compreensões sobre si próprio, dos alunos, da matéria, do currículo, das estratégias de ensino e da avaliação relacionadas com a facilitação da aprendizagem dos alunos. [...]. Ser professor é mais amplo, já que a atuação docente não está limitada às atividades realizadas dentro de uma sala de aula [...]. [...] Abrange [...] sua participação na instituição escolar, numa comunidade profissional com características, normas e culturas próprias (Reali \& Reyes, 2009, p. 13).

Portanto, pode-se dizer que a formação do professor ocorre numa contínua reflexão dos aprendizados dessas duas dimensões. No contexto da EPT, de acordo com Bacich e Moran (2018), o professor é o principal designer de roteiros personalizados e grupais de aprendizagem da mesma forma que é também um mentor/orientador de projetos profissionais e de vida dos seus alunos. Por outro lado, Bacich, Tanzineto e Trevisani (2015), relatam que os professores ainda não detêm o conhecimento e a habilidade necessária para a utilização das tecnologias da atualidade em seu ensino. E que esta dificuldade não se refere à falta de interesse.

Conforme Pereira, Conte e Dias (2017), essas competências necessárias não só para o uso, como para o desenvolvimento efetivo de uma cultura digital, ainda causa sentimentos de estranhamento, incompetência ou de desconfiança em muitos professores. A alfabetização ou letramento digital pressupõe habilidades básicas para a utilização das tecnologias digitais. $\mathrm{O}$ letramento digital refere-se à competência relacionada às habilidades de pesquisa, avaliação, reflexão e criticidade das informações disponíveis na internet, bem como o uso das ferramentas digitais (Behar, 2013). Freitas (2010), propõe a seguinte reflexão: um professor que pertence a outra cultura, um estrangeiro digital, como pode se situar diante do aluno, um nativo digital? Dessa indagação Freitas (2010) salienta que se torna necessário que os professores reconheçam que os alunos detêm um letramento digital no sentido amplo e não apenas técnico e cita Pasolini, em seu livro Jovens Infelizes: "Não se pode ensinar se ao mesmo tempo não se aprende" (1990, p.132).

O professor da rede federal de educação (EPT) tem por desafio ensinar os estudantes para a compreensão do mundo do trabalho e para o conhecimento do papel dos avanços tecnológicos para a sociedade atual (Machado, 2008). Gauthier et al. (1998), relata que existem ideias pré-concebidas no que se refere aos saberes docentes: conhecer o conteúdo, ter talento, ter bom senso, seguir a intuição, ter conhecimento e ter cultura. No entanto, Tardif (2002) sugere que se torna necessário repensar a formação dos professores com base no seu contexto de atuação. Essa formação deve buscar equiparação entre conhecimento produzido e desenvolvimento a partir da prática na sala de aula.

Azevedo (2012) assevera que é necessário priorizar questões como: modelos pedagógicos mais construtivistas e participativos, necessidade de mediação pedagógica e tecnológica e estratégias de aprendizagem adequadas aos meios desta modalidade de ensino.

\section{Considerações Finais}

O presente artigo teve como objetivo discutir o arcabouço teórico sobre o uso das Metodologias Ativas (MA's) na Educação Profissional e Tecnológica. Para tal, fez-se necessário refletir sobre o contexto educacional brasileiro sob a égide da 
Educação Profissional, principalmente em relação ao uso das MA's e as TICs no percurso formativo; o perfil dos alunos partícipes fundamentais deste processo e o papel do professor.

A partir das elucidações feitas, é possível perceber que o uso das MA’s é uma atividade incipiente que envolve múltiplas questões, tais como: perfil/geração dos alunos; formação pedagógica dos professores; a proposta curricular dos cursos e; o pouco aprofundamento a respeito da utilização de MA's na EPT.

Torna-se necessário romper com a dualidade aluno (nativo digital) e professor (estrangeiro digital); buscar uma discussão aprofundada sobre as perspectivas e os desafios de projetos pedagógicos mais inclusivos e que dialoguem com as reais necessidades do mercado de trabalho e o percurso formativo dos alunos; capacitação dos professores e; a reforma ou infusão de uma educação protagonista, ativa e reflexiva no âmbito da EPT.

Para pesquisas futuras, recomendamos investigar as expectativas e desafios de alunos e professores a respeito do uso das MA's e as TIC's no âmbito da EPT e como a EPT tem discutido em âmbito de reformas estruturais curriculares a sua inclusão nos projetos pedagógicos.

\section{Referências}

Andrade, L. G. da S. B et al. (2020). Geração Z e as metodologias ativas de aprendizagem: desafios na educação profissional e tecnológica. Revista Brasileira de Educação Profissional e Tecnológica, 1 (18), 1-18. http://www2.ifrn.edu.br/ojs/index.php/RBEPT/article/view/8575

Andrade, L. G. da S. B., \& Ferrete, R.B. (2019). Metodologias ativas e a educação profissional e tecnológica: invertendo a sala de aula em vista de uma aprendizagem significativa. EPT em Revista, 3 (2), 86-98. https://ojs.ifes.edu.br/index.php/ept/article/view/451/398

Araujo, R. M. de L., \& Frigotto, G. (2015). Práticas pedagógicas e ensino integrado. Revista Educação em Questão, 52 (38), 61-80. https://periodicos.ufrn.br/educacaoemquestao/article/view/7956/5723

Araújo, U. F. (2011). A quarta revolução educacional: a mudança de tempos, espaços e relações na escola a partir do uso de tecnologias e da inclusão social. ETD: educação temática digital. Website da FAE - UNICAMP. http://www.fae.unicamp.br/revista/index.php/etd/article/view/2279

Azevedo, A. B. de. (2012). Desafios da docência na Educação a Distância. https://node1.123dok.com/dt05pdf/123dok_br/002/398/2398448.pdf.pdf?X-AmzContent-Sha256=UNSIGNED-PAYLOAD\&X-Amz-Algorithm=AWS4-HMAC-SHA256\&X-Amz-

Credential=7PKKQ3DUV8RG19BL\%2F20210716\%2F\%2Fs3\%2Faws4_request\&X-Amz-Date=20210716T141034Z\&X-Amz-SignedHeaders=host\&X-

Amz-Expires=600\&X-Amz-Signature=e7ff98f0d49d2165abd21e9eea1e6ccc74d895f4027a5a56a8822b4c7e89b29d

Bacich, L., \& Moran, J. (2018). Metodologias ativas para uma educação inovadora: uma abordagem teórico-prática. Porto Alegre: Penso.

Bacich, L., \& Tanzineto, A. N., \& Trevisani, F. M. (Org.). (2015). Ensino híbrido: personalização e tecnologia na educação. Porto Alegre: Penso.

Barbosa, E. F., \& Moura, D. G. (2013). Metodologias ativas de aprendizagem na educação profissional e tecnológica. SENAC Journal of Education and Work, 39 (2), 48-67. https://www.bts.senac.br/bts/article/view/349

Barcellos, M.E.et al. (2017). A reforma do ensino médio e as desigualdades no Brasil. Revista Brasileira da Educação Profissional e Tecnológica, 2 (13), 118136. http://www2.ifrn.edu.br/ojs/index.php/RBEPT/article/view/6127/pdf

Behar, P.A. (Org). (2013). Competências em educação à distância. Porto Alegre: Penso.

Bonwell, C. C., \& Eison, J. A. (1991). Active learning: creating excitement in the classroom. Recuperado de: http://www.eric.ed.gov/PDFS/ED340272.pdf

Brasil. Lei $n^{\circ}$ 9.394, de 20 de dezembro de 1996. (1996). Estabelece as diretrizes e bases da educação nacional. Brasília, DF.

Brasil. Ministério da Educação. Secretaria da Educação Básica. Base Nacional Comum Curricular - Ensino Médio. Brasília-DF.

Carneiro, R. P. (2012). Reflexões acerca do processo ensino aprendizagem na perspectiva freireana e biocêntrica. Revista Thema, 9 (2). https://periodicos.ifsul.edu.br/index.php/thema/article/view/145

Diesel, A., Baldez, A. L. S., \& Martins, S.N. (2017). Os princípios das metodologias ativas de ensino: uma abordagem teórica. Revista Thema, 14 (10), 268-288.

Freire, P. (2013). Pedagogia do oprimido. Rio de Janeiro: Paz e Terra.

Freitas, M. T. (2010). Letramento Digital e a Formação de Professores. Educação em Revista, 26 (3), $335-352$.

Frigotto, G., Ciavatta, M., \& Ramos, M. (Orgs.). (2005). Ensino Médio Integrado: concepções e contradições. São Paulo: Cortez.

Gauthier, C.et al. (1998). Por uma teoria da Pedagogia. Ijuí: Unijuí..

Gil, A. C. (2002). Como elaborar projetos de pesquisa. (4a. ed.). São Paulo: Atlas. 
Research, Society and Development, v. 10, n. 10, e354101018880, 2021 (CC BY 4.0) | ISSN 2525-3409 | DOI: http://dx.doi.org/10.33448/rsd-v10i10.18880

Godoy. A. S. (1995). Pesquisa qualitativa: tipos fundamentais. Revista de administração de Empresas, 35 (3), 20-29. https://www.scielo.br/j/rae/a/ZX4cTGrqYfVhr7LvVyDBgdb/?lang=pt\&format=pdf

Goldberg, D. E. (2010). The missing basics \& other philosophical reflections for the transformation of engineering education. Website do Philsci Arquive. http://philsci-archive.pitt.edu/4551/

Kleiman, A. B., \& Marques, I. B. A. S. (2018). Letramentos e tecnologias digitais na educação profissional e tecnológica. Revista Brasileira da Educação Profissional e Tecnológica, 2 (15), 1-20. http://www2.ifrn.edu.br/ojs/index.php/RBEPT/article/view/7514

Libâneo, J. C. (2013). Didática. (2a ed.). São Paulo: Cortez.

Lima, M. et al. (2019). Metodologia ativa: um estudo de caso no ensino médio técnico integrado no IFMS - Campus Nova Andradina. III Encontro Internacional de Gestão, Desenvolvimento e Inovação. Naviraí, MS.

Macedo, M. L. R., Freitas, C. N. P., \& Bezerra, D. P., \& Santos, F. A. A. (2019). Práticas educativas na educação profissional e tecnológica à luz da neuroeducação. Brazilian Journal of Development, 5 (11), 23110-23128.

Machado, L. R. de S. (2008). Diferenciais inovadores na formação de professores para a educação profissional. Revista Brasileira da Educação Profissional e Tecnológica, 1 (1), 8-22.

Mattar, J. (2017). Metodologias Ativas: para a educação presencial, blended e a distância. São Paulo: Artesanato Educacional.

Meyers, C., \& Jones, T.B. (1993). Promoting active learning. San Francisco: Jossey Bass.

Moran, J. (2015). Mudando a educação com metodologias ativas. http://www2.eca.usp.br/moran/wpcontent/uploads/2013/12/mudando_moran.pdf

Moura, D.H. (2008). A formação de docentes para a educação profissional e tecnológica. Revista Brasileira da Educação Profissional e Tecnológica, 1 (1), 23 38. http://www2.ifrn.edu.br/ojs/index.php/RBEPT/article/view/2863/1004

Palfrey, J., \& Gasser, U. (2011). Nascidos na era digital: entendendo a primeira geração dos nativos digitais. Porto Alegre: Artmed.

Pereira, S. F., Conte, E., \& Dias, M.G. (2017). Competência humana e digital - fronteiras ao aprender cooperativo. Revista Educação e Emancipação, 10 (2), 122-146. http://www.periodicoseletronicos.ufma.br/index.php/reducacaoemancipacao/article/view/7390

Reali, A. M. M. R., \& Reyes, C. R. (2009). Reflexões sobre o fazer docente. São Carlos: EdUFSCar.

Santos, F. A. A et al. (2018). Práticas Pedagógicas Integradoras no Ensino Médio Integrado. Holos, 6, 185-199. http://www2.ifrn.edu.br/ojs/index.php/HOLOS/article/view/7611/pdf

Saviani, D. (2011). História das ideias pedagógicas no Brasil. (3a.ed.). Campinas/SP: Autores Associados.

Severino, A. J. (2007). Metodologia do trabalho científico. (23a ed.). São Paulo: Cortez.

Severo, C. E. P. (2018). Os efeitos educativos de práticas pedagógicas interdisciplinares baseadas em projetos na Educação Profissional e Tecnológica. Revista Interdisciplinaridade, (12), 32-46. https://revistas.pucsp.br/index.php/interdisciplinaridade/article/view/36783

Shah, S., \& Nihalani, M. (2012). Stress free environment in classroom: impact of humor in student satisfaction. Recuperado de: http://www.grin.com/en/ebook/192216/stress-free-environment-in-classroom-impact-of-humor-in-student-satisfaction\#inside

Silberman, M. (1996). Active learning: 101 strategies do teach any subject. Massachusetts: Ed. Allyn and Bacon.

Silveira, R. B., Gonçalves, L.F., \& Maraschin, M.S. (2017). A formação de professores na educação profissional e tecnológica e a complexidade que envolve a permanência e êxito dos estudantes. Revista Brasileira da Educação Profissional e Tecnológica, 2 (13), 81-93.

Tardif, M. (2002). Saberes Docentes e Formação Profissional. Petrópolis: Vozes.

Trevelin, A. T. C., Pereira, M. A. A., \& O. Neto, J. D. (2013). A utilização da sala de aula invertida em cursos superiores de tecnologia: comparação entre o modelo tradicional e o modelo invertido flipped classroom adaptado aos estilos de aprendizagem. Website da UNED. https://www2.uned.es/revistaestilosdeaprendizaje/numero_12/articulos/articul o_8.pdf

Valente, J. A. (2014). Blended Learning e as mudanças no Ensino Superior: a proposta da sala de aula invertida. Recuperado de: http://ojs.c3sl.ufpr.br/ojs2/index.php/educar 